\title{
SYSTEMIC LUPUS ERYTHEMATOSUS - DESCRIPTIVE STUDY OF 134 PATIENTS FROM A SINGLE CENTER
}

\author{
Alina Dima ${ }^{1,2}$, Camelia Badea ${ }^{1,2}$, Eugenia Balanescu$^{1}$, Simona Caraiola ${ }^{1,2}$, Caterina Delcea ${ }^{1,2}$, \\ Razvan Ionescu ${ }^{1,2}$, Ciprian Jurcut ${ }^{3}$, Adriana Nicolau ${ }^{1,2}$, Valer Pompilian ${ }^{1,2}$, Doina Ramba ${ }^{1}$, \\ Cristian Baicus ${ }^{1,2}$, Gheorghe Andrei Dan ${ }^{1,2}$ \\ ${ }^{1}$ Colentina Research Center, Colentina Clinical Hospital, Bucharest, Romania \\ ${ }^{2}$ Carol Davila University of Medicine and Pharmacy, Bucharest, Romania \\ ${ }^{3}$ Dr. Carol Davila Central University Emergency Military Hospital, Bucharest, Romania
}

\begin{abstract}
Introduction. Systemic lupus erythematosus (SLE) is a chronic autoimmune disease of unknown origins with increasing prevalence worldwide. Lupus clinical and immunological features are complex and heterogeneous, but peculiar characteristics in different population were described.

Aim. Description of specific clinical and biological features of SLE patients.

Methods. 134 patients fulfilling the 2012 SLE Systemic Lupus International Collaborating Clinic criteria were enrolled. Baseline characteristics and biological features (such as sex, age, age at disease onset, disease duration, tobacco and alcohol habits, cardiovascular and fracture risk factors) were collected in all consenting patients prospectively included. Also, disease activity scores such as Systemic Lupus Activity Measure (SLAM), European Consensus Lupus Activity Measurement, Systemic Lupus Erythematosus Disease Activity Index, and accrual damage Systemic Lupus International Collaborating Clinics/American College of Rheumatology index were assessed when data needed for these scores were available.

Results. A number of 134 SLE patients, majority of feminine sex $(89.6 \%)$ were enrolled. The mean \pm SD age at inclusion and onset age were $46.4 \pm 12.9$ years and $36.5 \pm 12.2$ years. $19.4 \%$ of patients included were current smokers. Regarding comorbidities, $8.5 \%$ associated diabetes and $41.8 \%$ hypertension. Anti-deoxyribonucleic acid antibodies were identified in the antecedents of only $50.4 \%$ of the searched cases; higher proportion of positivity was found for lupus anticoagulant, respectively $70.9 \%$. Joint involvement was the most frequent clinical criterion used to sustain the lupus diagnosis (110 patients, $82.1 \%$ ), while the hematological one the most frequent involvement at inclusion (50 patients, $37.3 \%$ ). $67.9 \%$ of patients presented SLAM score results less or equal to 5 points, $10.4 \%$ results between 5 and 8 points, and $21.6 \%$ of more or equal to 8 points. The majority of patients enrolled were under corticosteroid treatment (109 patients, 81.3\%) and also an important part was receiving Hydroxychloroquine (108 patients, 80.6\%).

Conclusion. In this cross-sectional study, we presented important data related to general characteristics, biological parameters, immunological features, disease scores, and treatment principles in a single-center sample of SLE patients.
\end{abstract}

Keywords: systemic lupus erythematosus, disease scores, corticosteroid

\section{INTRODUCTION}

Systemic lupus erythematosus (SLE) is an autoimmune pathology with net feminine predominance (1-3) and wide broad spectrum of manifestations and so, a very heterogeneous clinical presentation (4-6). The reported incidence and prevalence varies largely, with increased rates observed in recent years. Besides a real increase in SLE occurrence, greater recognition of mild disease cases as well as the introduction of more sensitive criteria, the 2012 SLE Systemic Lupus International Collaborating Clinic (SLICC) criteria, are also involved in recent observed trends (1). Therefore, SLE reported incidence varies from 2.0 to 7.6 per 100,000 inhabitants in the United States, while in Europe it was reported from 3.7 in Nottingham to 4.8 per 100,000 inhabitants in Sweden (5). Moreover, SLE prevalence varies between 14.6 per 100,000 inhabitants in New York to

Correspondence address:

Alina Dima, MD; Colentina Research Center, Colentina Clinical Hospital, 19-21 Stefan cel Mare Road, Bucharest, Romania

E-mail: alina_dima@outlook.com 
as high as 50.8 per 100,000 inhabitants in San Francisco (5). In Norway, SLE prevalence was 52.0 and lower in Sweden 36.3-39.0 per 100,000 inhabitants $(5,7)$. In Asia, prevalence of 30.0 to 50.0 per 100,000 inhabitants was reported (8). Also, in Asian immigrants a 1.5 higher lupus incidence than in European descendents from Oslo was observed (7). Much higher prevalence, up to 90 cases per 100,000 inhabitants was reported in Spain (1). SLE is more frequently encountered and associated with more severe disease in African American when compared with Caucasion populations (9).

All these data are showing that SLE is not a rare occurence (5), but a pathology with important and increasing rates of incidence and prevalence $(1,10)$. Also, SLE's features are not homogeneous worldwide, specific characteristics in regard with genetic and environmental determinants being previously described (11-18).

SLE is characterized by successive periods of remission and flares. Generally, disease activity in newly diagnosed patients appears to decrease over the first 5 years after disease onset. On the contrary, accrual damage is increasing with simultaneously increasing in antinuclear antibodies (ANA), lupus anticoagulant (LAC), and anti-deoxyribonucleic acid (DNA) positivity (19). Complete remission (defined as at least 3 years period without clinical activity, normal $\mathrm{C} 3$ complement, and negative anti-DNA in absence of corticosteroid treatment) might be achieved in up to $15.0 \%$ of all patients; but even after 10 years of remission, new lupus flares might occur (20).

There is scarce information regarding SLE characteristics in Romanian population. Therefore, the aim of this study was to describe demographic features, clinical involvements, biological markers, disease scores, as well as therapeutic principals of SLE patients in a tertiary-care hospital in Bucharest, Romania.

\section{METHODS}

\section{Patients' inclusion}

A prospective, cross-sectional study with inclusion of 134 adult (older than 18 years) patients fulfilling the 2012 SLE SLICC criteria (21) was realized. All patients signed an informed consent at inclusion. This study was approved by the Colentina Hospital Ethics Committee.

\section{General data}

The same protocol was completed in all subjects. At baseline, general patients' data such as sex, age, age at disease onset, disease duration, tobacco and alcohol habits, cardiovascular risk factors (blood pressure, cardiovascular history), and fracture risk factors (patient and his relatives' history of osteoporotic fracture) were collected in all patients. Moreover, data on treatment principles was recorded: full treatment at inclusion, as well as the history of specific treatment used in lupus disease, such as corticosteroids, immunosuppressive drugs or antimalarial medication.

\section{Biological and immunological parameters}

All medical and biological data were collected from patients' hospital files. No specific laboratory or imaging tests were assessed for this study. Biological and immunological parameters were all recorded when present in patients' ongoing or previous hospital files (all parameters recorded at inclusion were determined within 7 days of the enrollment in the study). The immunological determinations are done in the hospital laboratory by Enzyme Linked Immunosorbent Assay (ELISA). Accordingly, the data quality on biological and immunological parameters is not high, since there are SLE related parameters lacking (e.g. data related to autoimmune hemolytic anemia were generally missing: Coombs test was rarely present between the biological parameters determined, haptoglobin is not determined in our hospital's laboratory).

\section{SLE active involvement and disease scores}

SLE clinical characteristics were defined according to the 2012 SLICC diagnosis criteria with the exception of joint involvement where not only synovitis but also arthralgia with inflammatory features was considered. Data regarding SLE active clinical involvements were recorded either by interviewing the patient, by clinical examination, or from each patient's hospital file.

Further, three disease activity scores were assessed: Systemic Lupus Activity Measure (SLAM) (22), European Consensus Lupus Activity Measurement (ECLAM) (23), and Systemic Lupus Erythematosus Disease Activity Index (SLEDAI) (24) respectively. Even if completed prospectively, assessing these scores is however complex and so accurate lupus activity measure might be challenging. For the SLEDAI score, anti-DNA antibodies were determined only in part of the patients, so this score 
was assessed without the item corresponding to the anti-DNA antibodies. Moreover, in cases with negative ANA, the anti-DNA was also considered negative.

Irreversible accrual damage was assessed by the Systemic Lupus International Collaborating Clinics/ American College of Rheumatology (SLICC/ACR) Damage Index (25).

\section{Statistical analysis}

Data were presented as mean with standard deviation (SD) or as median (med) and, quartiles 1 and 3 (q1; q3), for variables with normal, respectively without normal distribution. Nominal variables were expressed as percentages.

\section{RESULTS}

\section{General data}

General data are presented in Table 1. A total of 134 patients were included in the analysis, of which the vast majority was females, 120 patients $(89.6 \%)$. The proportions of patients between 35-50 years and over 50 years were comparable, 50 patients $(37.7 \%)$ vs. 59 patients (44.0\%). Less patients, 25 (18.7\%) were younger than 35 years. On the contrary, the highest proportion of our study sample, 63 patients (47.7\%) had the lupus onset before the age of 35 years. 19 patients $(14.4 \%)$ presented with late disease onset (meaning more than 50 years).

Regarding lupus duration, the majority of the enrolled patients had a disease history longer than 10 years. 20 patients $(15.2 \%)$ were newly diagnosed, with less than 1 year from the disease diagnosis.

Among the entire group, 42 patients (38.8\%) were current or former smokers and 14 patients (15.7\%) admitted alcohol consumption. There were 56 patients $(41.8 \%)$ known with high blood pressure values and 8 patients $(8.5 \%)$ with diabetes. Cardiovascular history (ischemic heart disease or stroke) was present in 15 patients (16.9\%).

\section{Biological and immunological parameters}

We first analyzed the spectrum of immunological features. Regarding complement levels, the med (q1; q3) of $\mathrm{C} 4$ and $\mathrm{C} 3$ complement were $0.16(0.10 ; 0.22)$ and $1.02(0.82 ; 1.15) \mathrm{g} / \mathrm{L}$.

The available data on auto antibodies profile was limited: anti-DNA antibodies were determined at enrollment in 81 patients, anti-Sm in 16 patients, anti-
TABLE 1. Subjects' baseline characteristics

\begin{tabular}{|l|c|}
\hline Characteristic & \\
\hline Gender, $\mathrm{F} / \mathrm{M}(\% \mathrm{~F})$ & $120 / 14(89.6)$ \\
\hline Age at inclusion (years), mean \pm SD & $46.4 \pm 12.9$ \\
\hline$\leq 35$ years, $\mathrm{n}(\%)$ & $25(18.7)$ \\
\hline $35.1-49.9$ years, $\mathrm{n}(\%)$ & $50(37.3)$ \\
\hline$\geq 50$ years, $\mathrm{n}(\%)$ & $59(44.0)$ \\
\hline $\begin{array}{l}\text { Age at SLE diagnosis (years), } \\
\text { med (q1; } \mathrm{q} 3)\end{array}$ & $36.5 \pm 12.2$ \\
\hline$\leq 35$ years, $\mathrm{n}(\%)$ & $63(47.7)$ \\
\hline $35.1-49.9$ years, $\mathrm{n}(\%)$ & $50(37.9)$ \\
\hline$\geq 50$ years, $\mathrm{n}(\%)$ & $19(14.4)$ \\
\hline $\begin{array}{l}\text { SLE's disease duration (years), } \\
\text { mean } \pm \text { SD }\end{array}$ & $9.0(4.0-14.0)$ \\
\hline$\leq 1$ year, $\mathrm{n}(\%)$ & $20(15.2)$ \\
\hline $1.1-5$ years, $\mathrm{n}(\%)$ & $24(18.1)$ \\
\hline $5.1-9.9$ years, $\mathrm{n}(\%)$ & $31(23.5)$ \\
\hline$\geq 10$ years, $\mathrm{n}(\%)$ & $57(43.2)$ \\
\hline Weight (kg), mean \pm SD & $68.2 \pm 13.9$ \\
\hline Height (cm), mean \pm SD & $163.9 \pm 8.2$ \\
\hline BMI (kg/m²), mean \pm SD & $25.4 \pm 5.2$ \\
\hline Smoking, yes/no (\%yes) & $42 / 108(38.8)$ \\
\hline Active smoker, yes/no (\%yes) & $21 / 108(19.4)$ \\
\hline Former smoker, yes/no (\%yes) & $21 / 108(19.4)$ \\
\hline Alcoholism, yes/no (\%yes) & $14 / 117(15.7)$ \\
\hline $\begin{array}{l}\text { Systolic blood pressure (mmHg), } \\
\text { mean } \pm \text { SD }\end{array}$ & $122.6 \pm 16.9$ \\
\hline $\begin{array}{l}\text { Diastolic blood pressure (mmHg), } \\
\text { mean } \pm \text { SD }\end{array}$ & $75.1 \pm 10.0$ \\
\hline Hypertension, yes/no (\%yes) & $5 / 125(8.5)$ \\
\hline Diabetes, yes/no (\%yes) & \\
\hline $\begin{array}{l}\text { Cardiovascular antecedents, } \\
\text { yes/no (\%yes) }\end{array}$ & \\
\hline
\end{tabular}

Ro in 32 patients, and anti-La in 11 patients. Regarding the history of antibodies' positivity, data were not very precise. Each antibody was considered positive if at least one positive determination was identified in the patient's medical files, negative if all determinations were negative and otherwise data was considered missing. Therefore, as these antibodies were not determined simultaneously, the proportion of their positivity rests only indicative in this research (Table 2). We next examined the inflammatory syndrome, blood count, and biochemistry parameters, as well as urine exam as presented in Table 3.

TABLE 2. Immunological features during disease course and at enrolment

\begin{tabular}{|l|c|}
\hline \multicolumn{2}{|l|}{ Characteristic } \\
\hline $\begin{array}{l}\text { Complement C3 }(\mathrm{g} / \mathrm{L}), \\
\text { med }(\mathrm{q} 1 ; \mathrm{q} 3) \mathrm{n}=122\end{array}$ & $1.02(0.82 ; 1.15)$ \\
\hline $\begin{array}{l}\text { Complement } \mathrm{C} 4(\mathrm{~g} / \mathrm{L}), \\
\text { med }(\mathrm{q} 1 ; \mathrm{q} 3) \mathrm{n}=121\end{array}$ & $0.16(0.10 ; 0.22)$ \\
\hline $\begin{array}{l}\text { ANA at inclusion }(\mathrm{Ul} / \mathrm{mL}), \\
\text { med }(\mathrm{q} 1 ; \mathrm{q} 3) \mathrm{n}=49\end{array}$ & $122.5(39.7 ; 138.9)$ \\
\hline
\end{tabular}




\begin{tabular}{|c|c|}
\hline \multicolumn{2}{|l|}{ Characteristic } \\
\hline $\begin{array}{l}\text { anti-DNA at inclusion }(\mathrm{Ul} / \mathrm{mL}) \\
\text { med }(\mathrm{q} 1 ; \mathrm{q} 3) \mathrm{n}=81\end{array}$ & $83.9(24.0 ; 416.1)$ \\
\hline $\begin{array}{l}\text { anti-DNA history, } \\
\text { pos/neg (\% pos) }\end{array}$ & $60 / 59(50.4)$ \\
\hline $\begin{array}{l}\text { anti-Sm at inclusion }(\mathrm{Ul} / \mathrm{mL}) \text {, med } \\
\text { (q1; q3) } n=16\end{array}$ & $3.34(1.96 ; 17.66)$ \\
\hline anti-Sm history, pos/neg (\% pos) & $17 / 55(23.6)$ \\
\hline $\begin{array}{l}\text { anti-Ro at inclusion }(\mathrm{UI} / \mathrm{mL}) \\
\text { med }(\mathrm{q} 1 ; \mathrm{q} 3) \mathrm{n}=32\end{array}$ & $18.6(1.56 ; 94.06)$ \\
\hline anti-Ro history, pos/neg (\% pos) & $48 / 43(52.7)$ \\
\hline $\begin{array}{l}\text { anti-La at inclusion }(\mathrm{Ul} / \mathrm{mL}) \text {, med } \\
(\mathrm{q} 1 ; \text { q3) } n=11\end{array}$ & $2.11(1.23 ; 13.94)$ \\
\hline anti-La history, pos/ neg (\% pos) & $15 / 45(25.0)$ \\
\hline LAC history, pos/ neg (\% pos) & $39 / 16(7.9)$ \\
\hline IgM aCL history, pos/ neg (\% pos) & $7 / 39(15.2)$ \\
\hline IgG aCL history, pos/ neg (\% pos) & $5 / 43(10.4)$ \\
\hline $\begin{array}{l}\text { IgM aß2 GPI history, } \\
\text { pos/neg ( } \% \text { pos) }\end{array}$ & $1 / 3(25.0)$ \\
\hline $\begin{array}{l}\text { IgG aß2 GPI history, } \\
\text { pos/neg (\% pos) }\end{array}$ & $2 / 39(4.9)$ \\
\hline
\end{tabular}

TABLE 3. Biological parameters at enrolment

\begin{tabular}{|c|c|}
\hline Characteristic & \\
\hline $\operatorname{ESR}(\mathrm{mm} / \mathrm{h}), \operatorname{med}(\mathrm{q} 1 ; \mathrm{q} 3) \mathrm{n}=133$ & $17.0(10.0 ; 31.0)$ \\
\hline $\operatorname{CRP}(\mathrm{g} / \mathrm{dL}), \operatorname{med}(\mathrm{q} 1 ; \mathrm{q} 3) \mathrm{n}=128$ & $2.3(0.9 ; 5.9)$ \\
\hline $\begin{array}{l}\text { Fibrinogen (mg/dL), } \\
\text { med }(q 1 ; q 3) n=77\end{array}$ & $352.0(323.0 ; 407.5)$ \\
\hline $\begin{array}{l}\text { Leucocytes }(n / \mu L) \\
\text { med }(q 1 ; q 3) n=134\end{array}$ & $6,660(5,065 ; 8,770)$ \\
\hline $\begin{array}{l}\text { Neutrophils }(n / \mu L) \\
\text { med }(q 1 ; q 3) n=134\end{array}$ & $4,065(5,065 ; 8,770)$ \\
\hline $\begin{array}{l}\text { Lymphocytes }(n / \mu L) \\
\text { med (q1; q3) } n=134\end{array}$ & $1,655(1180 ; 2180)$ \\
\hline $\begin{array}{l}\text { Hemoglobin }(\mathrm{mg} / \mathrm{dL}) \\
\text { mean } \pm \mathrm{SD} n=134\end{array}$ & $12.5 \pm 1.7$ \\
\hline $\begin{array}{l}\text { Hematocrit (\%), } \\
\text { med (q1; q3) n=134 }\end{array}$ & $38.1(35.5 ; 42.0)$ \\
\hline $\mathrm{MCV}(\mathrm{fL})$, mean $\pm \mathrm{SD} n=134$ & $83.9 \pm 14.2$ \\
\hline $\begin{array}{l}\text { Platelets }(n / \mu L) \\
\text { med }(q 1 ; q 3) n=134\end{array}$ & $\begin{array}{c}244,500(191,750 ; \\
298,750)\end{array}$ \\
\hline $\begin{array}{l}\text { Creatinine }(\mathrm{mg} / \mathrm{dL}) \\
\text { med }(\mathrm{q} 1 ; \mathrm{q} 3) \mathrm{n}=131\end{array}$ & $0.73(0.65 ; 0.91)$ \\
\hline Urea $(\mathrm{mg} / \mathrm{dL})$, med $(\mathrm{q} 1 ; \mathrm{q} 3) \mathrm{n}=43$ & $34.0(27.8 ; 45.1)$ \\
\hline $\begin{array}{l}\text { Albumin }(\mathrm{mg} / \mathrm{dL}) \\
\text { med }(\mathrm{q} 1 ; \mathrm{q} 3) \mathrm{n}=97\end{array}$ & $4.2(3.9 ; 4.4)$ \\
\hline $\begin{array}{l}\text { Total cholesterol }(\mathrm{mg} / \mathrm{dL}) \\
\text { med }(\mathrm{q} 1 ; \mathrm{q} 3) \mathrm{n}=105\end{array}$ & $181.2(158.2 ; 221.7)$ \\
\hline $\begin{array}{l}\mathrm{HDL}-\text { cholesterol }(\mathrm{mg} / \mathrm{dL}) \text {, } \\
\text { med }(\mathrm{q} 1 ; \mathrm{q} 3) \mathrm{n}=86\end{array}$ & $56.8(46.5 ; 69.5)$ \\
\hline $\begin{array}{l}\mathrm{LDL}-\text { cholesterol }(\mathrm{mg} / \mathrm{dL}) \\
\text { med }(\mathrm{q} 1 ; \mathrm{q} 3) \mathrm{n}=80\end{array}$ & $106.1(82.4 ; 122.8)$ \\
\hline $\begin{array}{l}\text { Tryglicerides }(\mathrm{mg} / \mathrm{dL}) \\
\text { med }(\mathrm{q} 1 ; \mathrm{q} 3) \mathrm{n}=77\end{array}$ & $102.8(78.7 ; 160.9)$ \\
\hline $\mathrm{LDH}(\mathrm{UI} / \mathrm{dL}), \operatorname{med}(q 1 ; q 3) \mathrm{n}=54$ & $211.5(164.0 ; 251.0)$ \\
\hline $\operatorname{TGP}(\mathrm{UI} / \mathrm{dL})$, med $(\mathrm{q} 1 ; \mathrm{q} 3) \mathrm{n}=129$ & $17.2(13.6 ; 23.0)$ \\
\hline GGT (UI/dL), med (q1; q3) n=97 & $20.0(15.0 ; 35.0)$ \\
\hline $\begin{array}{l}\text { Proteinuria/24 h }(\mathrm{mg}) \\
\text { med }(q 1 ; q 3) n=120\end{array}$ & $67.3(0.0 ; 125.0)$ \\
\hline $\begin{array}{l}\text { Proteinuria spot }(\mathrm{mg} / \mathrm{dL}) \text {, } \\
\text { med }(\mathrm{q} 1 ; \mathrm{q} 3) \mathrm{n}=128\end{array}$ & $17.0(0.0 ; 20.0)$ \\
\hline Hematuria, yes/no $n=128$ & $10 / 115$ \\
\hline Leucocituria, yes/no $n=128$ & $15 / 110$ \\
\hline
\end{tabular}

\section{Clinical criteria involvements}

The most frequent clinical criteria observed at inclusion were the hematological one $(37.3 \%)$, followed by the non-scarring alopecia (36.6\%), and joint involvement (32.3\%).

As shown in Table 4, joint appeared to be the most frequent involvement anytime, present in 100 patients $(82.1 \%)$. This was followed by the hematological (68.7\%) and cutaneous (64.9\%) ones, as well as by alopecia $(64.9 \%)$.

TABLE 4. Clinical involvements, anytime during disease course and at inclusion

\begin{tabular}{|l|c|}
\hline Characteristic & $87 / 47(64.9)$ \\
\hline $\begin{array}{l}\text { Cutaneous involvement anytime, } \\
\text { yes/no (\%yes) }\end{array}$ & $55 / 76(42.0)$ \\
\hline Ulcers anytime, yes/no (\%yes) & $85 / 46(64.9)$ \\
\hline $\begin{array}{l}\text { Nonscarring alopecia anytime, } \\
\text { yes/no (\%yes) }\end{array}$ & $110 / 24(82.1)$ \\
\hline $\begin{array}{l}\text { Joint involvement anytime, } \\
\text { yes/no (\%yes) }\end{array}$ & $45 / 87(34.1)$ \\
\hline Serositis anytime, yes/ no (\%yes) & $51 / 82(38.3)$ \\
\hline $\begin{array}{l}\text { Renal involvement anytime, } \\
\text { yes/no (\%yes) }\end{array}$ & $41 / 93(30.6)$ \\
\hline $\begin{array}{l}\text { Neurologic involvement anytime, } \\
\text { yes/no (\%yes) }\end{array}$ & $92 / 42(68.7)$ \\
\hline $\begin{array}{l}\text { Hematologic involvement anytime, } \\
\text { yes/no (\%yes) }\end{array}$ & $40 / 93(30.1)$ \\
\hline $\begin{array}{l}\text { Cutaneous involvement at inclusion, } \\
\text { yes/no (\%yes) }\end{array}$ & $11 / 123(8.2)$ \\
\hline \begin{tabular}{l} 
Ulcers at inclusion, yes/no (\%yes) \\
\hline $\begin{array}{l}\text { Nonscarring alopecia at inclusion, } \\
\text { yes/no (\%yes) }\end{array}$
\end{tabular} & $48 / 83(36.6)$ \\
\hline $\begin{array}{l}\text { Joint involvement at inclusion, } \\
\text { yes/no (\%yes) }\end{array}$ & $43 / 90(32.3)$ \\
\hline $\begin{array}{l}\text { Serositis at inclusion, yes/no (\%yes) } \\
\text { yenal involvement at inclusion, }\end{array}$ \\
\hline $\begin{array}{l}\text { Neurologic involvement at inclusion, } \\
\text { yes/no (\%yes) }\end{array}$ \\
\hline $\begin{array}{l}\text { Hematologic involvement at inclusion, } \\
\text { yes/no (\%yes) }\end{array}$ \\
\hline
\end{tabular}

\section{Clinical disease's features}

As presented in Table 5, Raynaud syndrome was associated in 58 patients (43.9\%). Also, secondary Sjogren's syndrome (S's S) diagnosis was found in the medical files of 24 patients $(18.0 \%)$. Xerostomia and xeroftalmia were affirmed by 22 patients (18.6\%) and 17 patients (14.5\%).

Antiphospholipid syndrome (APS) diagnosis was found in $28.7 \%$ patients, 28 patients $(21.2 \%)$ having had thrombosis and 21 patients $(17.0 \%)$ pregnancy pathology as APS's clinical features. Osteopenia was diagnosed in 14 patients (18.7\%) and osteoporosis in 19 patients $(25.3 \%)$. 
Not all percentages presented here are reported for the entire sample as the information were not always available; all data are presented in Table 5.

TABLE 5. Clinical associated conditions

\begin{tabular}{|l|c|}
\hline \multicolumn{2}{|l|}{ Characteristic } \\
\hline Raynaud syndrome, $\mathrm{n}(\%)$ & $58 / 74(43.9)$ \\
\hline S's S, $\mathrm{n}(\%)$ & $24 / 109(18.0)$ \\
\hline Xerostomia, n (\%) & $22 / 96(18.6)$ \\
\hline Xeroftalmia, n (\%) & $17 / 101(14.4)$ \\
\hline APS, n (\%) & $37 / 92(28.7)$ \\
\hline Thrombosis, n (\%) & $28 / 105(21.1)$ \\
\hline Pregnancy pathology, n (\%) & $21 / 102(17.0)$ \\
\hline Osteopenia, n (\%) & $14 / 75(18.7)$ \\
\hline Osteoporosis, n (\%) & $19 / 75(25.3)$ \\
\hline
\end{tabular}

\section{SLE disease scores}

The med (q1; q3) estimates of the SLE disease activity scores assessed are presented in Table 6 . Regarding the SLAM score results, we observed that 29 patients $(21.6 \%)$ were characterized by a high degree of lupus activity. Conversely, the majority of patients were expressing only low disease activity at enrollment, 91 of them $(67.9 \%)$ with less than 5 points on the SLAM score. The overall median SLICC damage index was low, with a med (q1; q3) of $1.0(0.0-2.0)$ points.

TABLE 6. SLE disease scores assessed at inclusion

\begin{tabular}{|l|c|}
\hline \multicolumn{2}{|l|}{ Characteristic } \\
\hline SLAM score, points med $(\mathrm{q} 1 ; \mathrm{q} 3) \mathrm{n}=134$ & $4.0(2.0 ; 7.0)$ \\
\hline SLAM $\leq 5$ points, $\mathrm{n}(\%)$ & $91(67.9)$ \\
\hline SLAM 5-8 points, $\mathrm{n}(\%)$ & $14(10.4)$ \\
\hline SLAM $\geq 8$ points, $\mathrm{n}(\%)$ & $29(21.6)$ \\
\hline ECLAM score, points med (q1; q3) & $2.0(1.0 ; 3.0)$ \\
\hline SLEDAI score, points med $(\mathrm{q} 1 ; \mathrm{q} 3)$ & $6.0(2.0 ; 10.0)$ \\
\hline $\begin{array}{l}\text { SLEDAI without anti-DNA, } \\
\text { points med (q1; q3) }\end{array}$ & $4.0(2.0 ; 8.5)$ \\
\hline $\begin{array}{l}\text { SLICC damage index, } \\
\text { points med (q1; } \mathrm{q} 3)\end{array}$ & $1.0(0.0 ; 2.0)$ \\
\hline
\end{tabular}

\section{Treatment's principles}

Table 7 shows the different therapeutic principles used in the SLE patients' management. The vast majority of patients were under corticosteroid treatment at inclusion, 109 patients $(81.3 \%)$, with med (q1; q3) corticosteroid daily dose of $10.0(5.0-20.0) \mathrm{mg}$ (all corticosteroid dosages were equated in $\mathrm{mg}$ of Prednisone). At inclusion, a history of 6.0 (2.0-12.0) years of corticosteroid use was present in the study patients.

Treatment with Hydroxychloroquine was also found in the majority of patients, 108 patients $(80.6 \%)$, with a $6.0(1.0-3.0)$ years median treatment duration. Mycophenolate Mophetil therapy was present in only 2 patients (1.5\%). Calcium and vitamin D supplements were administrated in $48.9 \%$, respectively $59.5 \%$ patients. Bisphosphonates were used in a quarter of the entire lot.

TABLE 7. Treatment's characteristics during disease course and at inclusion

\begin{tabular}{|c|c|}
\hline Characteristic & \\
\hline $\begin{array}{l}\text { Corticosteroids at inclusion, } \\
\text { yes/no (\%yes) }\end{array}$ & $109 / 25(81.3)$ \\
\hline $\begin{array}{l}\text { Corticosteroids at inclusion - daily } \\
\text { dose (mg/day), med(q1; q3)* }\end{array}$ & $10.0(5.0 ; 20.0)$ \\
\hline $\begin{array}{l}\text { Corticosteroids at inclusion - daily } \\
\text { dose }(\mathrm{mg} / \mathrm{kg} / \text { day }) \text {, med }(\mathrm{q} 1 ; \mathrm{q} 3)^{*}\end{array}$ & $0.2(0.1 ; 0.3)$ \\
\hline $\begin{array}{l}\text { Corticosteroids - duration (years), } \\
\text { med (q1; } 3 \text { ) }\end{array}$ & $6.0(2.0 ; 12.0)$ \\
\hline $\begin{array}{l}\text { Corticosteroids - iv administration, } \\
\text { yes/no (\%yes) }\end{array}$ & $29 / 96(23.2)$ \\
\hline $\begin{array}{l}\text { Hydroxychloroquine at inclusion, } \\
\text { yes/no (\%yes) }\end{array}$ & $108 / 26(80.6)$ \\
\hline $\begin{array}{l}\text { Hydroxychloroquine at inclusion - } \\
\text { daily dose (mg/day), med (q1; q3) }\end{array}$ & $\begin{array}{c}400.0 \\
(200.0 ; 400.0)\end{array}$ \\
\hline $\begin{array}{l}\text { Hydroxychloroquine - daily dose } \\
\text { (mg/kg/day), med(q1; q3) }\end{array}$ & $5.2(2.5 ; 6.3)$ \\
\hline $\begin{array}{l}\text { Hydroxychloroquine - duration } \\
\text { (years), med (q1; q3) }\end{array}$ & $6.0(1.0 ; 3.0)$ \\
\hline Metotrexate in present, yes/no (\%yes) & $2 / 132(1.5)$ \\
\hline $\begin{array}{l}\text { Mycophenolate Mophetil at inclusion, } \\
\text { yes/no (\%yes) }\end{array}$ & $2 / 132(1.5)$ \\
\hline Cyclophosphamide, yes/no (\%yes) & $1 / 133(0.7)$ \\
\hline Azathioprine, yes/no (\%yes) & 16/118 (11.9) \\
\hline Calcium, yes/no (\%yes) & $65 / 68(48.9)$ \\
\hline Vitamin D, yes/no (\%yes) & $79 / 54(59.4)$ \\
\hline Bisphosphonates, yes/no (\%yes) & $33 / 99(25.0)$ \\
\hline $\begin{array}{l}\text { Hypertention treatment, } \\
\text { yes/no (\%yes) }\end{array}$ & $54 / 80(40.3)$ \\
\hline Statines, yes/no (\%yes) & $31 / 103(23.1)$ \\
\hline
\end{tabular}

\section{DISCUSSION}

SLE is an autoimmune disease of unknown origin, with net feminine predominance. Rua-Figuera I (1) et al studied 4,024 SLE patients of which 90\% were women. Other authors also reported gender ratios around 9:1 in lupus $(2,19)$. Fernandez M. (3) et al observed little differences regarding gender distribution in SLE patients with different ethnicities, as follows: female sex in $93 \%$ of the Texan patients, $95 \%$ of the Puerto Rican, $89 \%$ of the African American, and $85 \%$ of the Caucasian ones. Referring to SLE age of onset, the reported female to male ratio was 7:1 in early onset and less discrepant in late onset lupus, namely 4: 1 (26). Also, das Chagas Medeiros (27) $\mathrm{MM}$ et al reported female to male ratios of 6.5: 1 in childhood SLE, 16.8: 1 in adult SLE, and 
only women were observed in late onset lupus. Although less affected in lupus, the male sex patients appear to have worse prognosis associated with greater damage at younger ages (28), as well as reduced survival (29).

Different means of the age at inclusion were reported for SLE patients, as follows: $43.3 \pm 11.7$ years (30), $35.3 \pm 14.5$ years (19), or $32.8 \pm 12.0$ years in Texan, $36.7 \pm 11.2$ years in Puerto Rican, $34.8 \pm 11.2$ years in African American or $41.0 \pm 13.3$ years in Caucasian patients (3).

Regarding lupus onset age, proportions of 7-16\% of patients aged over 50 years at lupus onset, defined as late onset, were found $(1,31,32)$. Also, at the time of diagnosis, median ages of $33(24,44)$ years, respectively of $33(22,42)$ years in the moment of first lupus symptoms were observed (1). Further, SLE onset age might vary among different populations; values of 30 years were reported in Chinese patients (33) and 47 years in Sweden (34). In a Korean sample, $14 \%$ of SLE patients presented a juvenile disease onset, $74 \%$ adult onset, and $12.4 \%$ late onset (32). It appears that a higher age of SLE occurrence is related to a negative impact on these patients' survival (32). In relation to the environmental factors, the age at onset appears to be higher in urban compared to rural residents (35).

Furthermore, referring to lupus disease duration until the moment of inclusion in different studies, mean reported periods vary largely, such as of approximately 10 years (3) or 6 years (19). In regard to different ethnicities, mean duration of 16 years was observed in Texan patients, 19 years in Puerto Rican, 16 years in African American, and 18 years in Caucasian ones (3). Jasmin $\mathrm{R}$ et al observed that $40 \%$ of the patients included had less than 5 years of disease evolution, 25\% between 6 and 10 years, and 35\% more than 10 years (36).

Late onset SLE seems to be characterized by lower disease activity than the subgroup of patients with early onset, accumulating a lower number of diagnostic criteria (31). In this regard, the renal involvement appears to be less frequent in late onset than in early onset lupus, $13.5 \%$ vs. $26.4 \%$ (26). Other authors reported higher occurrences for lupus nephritis at younger age: $70 \%$ in childhood SLE, $53 \%$ in adult SLE, and $13 \%$ in late SLE (27). Choi J.H. (32) et al observed more frequent fever, oral ulcers, nephritis, anemia, and thrombocytopenia in cases with juvenile lupus onset. These clinical differences are also involving different therapeutic strategies in early versus late onset lupus (37). It is to notice that even if it is associated with less severe SLE, the overall survival probability is reduced in late onset lupus, probably due to associated comorbidities (26).

In regard to tobacco habits, $17 \%$ of lupus patients were recorded to be actively smoking (1), as well as $12.0 \%$ of the Texan, $6.0 \%$ of the Puerto Rican, $14.0 \%$ of the African American, and up to $20.0 \%$ of the Caucasian lupus patients (3).

In connection with general data, we observed in our cross-sectional study that approximately $90 \%$ of the patients included were of feminine sex as previously reported $(1,2,19)$. The data regarding age at inclusion, SLE age of onset or disease duration observed in our study were, 46 years, 37 years, and 9 years, respectively; data that are not superimposable on those reported in other published reports. Also, a higher percent than previously reported, namely $19 \%$ of patients, presented with late lupus onset $(1,31,32)$.

ANA testing appears the most sensitive available biomarker in SLE diagnosis. Positive ANA were reported basically in all SLE patients, percents close to $100 \%$ being presented by Rua-Figueroa I. (1) et al, Jimenez S. (5) et al, Alonso M.D. (26) et al, PonsEstel G.J. (35) et al, or Cipriano E et al (38). In our data, we cannot compare the results regarding ANA determinations as these were not available with indirect immunofluorescence (IIF), the screening method recommended for ANA, but only with ELISA, method by which a much lower number of possible positive ANAs could be exposed. Similarly, the methods of determination used for anti-DNA research varies, from the homogeneous pattern observed in IIF (even if it appears that anti-DNA antibodies could be associated also with other patters, like speckled or nucleolar, and not only with the homogeneous one) (39) to anti-DNA as part of an extractable nuclear antigen (ENA) pattern, and finally to anti-DNA determined by ELISA. Moreover, various proportions of positivity were reported for the anti-DNA antibodies in SLE, like 38.5\% (40), 60.0\% (38) or $78.0 \%$ (5). The anti-DNA positivity seems greater in lupus with early onset when compared to late onset, $68 \%$ versus $49 \%$ (26). Similarly, greater percent of anti-DNA was observed in lupus with juvenile onset (32). Furthermore, anti-DNA positivity occurrence is greater in patients with urban when compared to rural residency, $73 \%$ versus $66 \%$ (5). Around half of the lupus patients included in this 
study presented history of at least one anti-DNA positivity.

In regard with other antibodies commonly determined in SLE, their positivity varies: anti-Sm were reported in 10\% (5) - $15 \%$ (38) - 23\% (23) lupus patients, anti-Ro in $25 \%$ (5) - 36\% (38), and anti-La in $12 \%$ (38) - 19\% (5). In our research we obtained higher than previously reported positivity, as the presence of these antibodies was recorded if at least once in the patient's history the determination was positive.

Furthermore, LAC positivity in $12 \%(38,40)$ $15 \%$ (5) of lupus populations was observed. The data presented in the literature in regard to antiphospholipid antibodies (APLAs) varies largely: $8 \%$ for aCL (40), $13 \%$ for IgM aCL, 24\% for IgG aCL (5), and $14 \%$ for a 32 GPI (40), respectively more than $50 \%$ for all diagnostic APLAs counted together (35). In our sample, we identified $71 \%$ patients with at least one positive LAC determination in their medical records.

Complement consumption is reported more frequently in juvenile SLE (32), and it is also encountered more often in early onset than older onset lupus, $91 \%$ versus $73 \%$ (26). Other reports presented complement consumption in 34\% (40) - 50\% (38) of lupus patients.

With respect to lupus heterogeneity, reports of renal involvement vary from $16 \%$ (2) - 27\% (38) $34 \%$ (1) - $41 \%$ (36) up to $50 \%$ (6) of patients. Lupus nephritis is one of the major involvements and a good therapeutic response of the renal impairment might predict a positive disease evolution (41).

Even if it is not one of the most severe or debilitating lupus involvements, the joint impairment appears to be one of the most common SLE features. Both arthralgia and arthritis counts up to more than $90 \%$ of lupus patients (35). Similarly to other organ involvements, the reported rate varies also in respect to the definition criteria used. So, arthritis was observed from $52 \%$ (36) up to $78 \%$ (1) - $84 \%$ (5) of patients enrolled. Oliveira-Santos (6) et al reported polyarthralgia in $57 \%$ of lupus patients. Also, arthralgia and arthritis seem more frequent in females when compared to males, $65 \%$ vs. $46 \%$ and $44 \%$ vs. $36 \%$ (4). Serositis was encountered in $8 \%(36)-20 \%$ (38) - 29\% (1) - 36\% (5) - 42\% (6) of lupus subjects. Furthermore, neurologic involvement was described in $8 \%(1,38)-10 \%(6)-27 \%(5)$ of the patients included. Hematological disorders were reported in $50 \%$ (38) - $60 \%$ (6) to $80 \%$ (1) of lupus patients.
Also, most SLE patients present with anemia during the disease course, (42) due to multiple mechanisms, such as simple anemia. Also, up to $10 \%$ of the SLE patients might have autoimmune hemolytic anemia (36).

In the lupus patients' sample presented here, the hematological involvement and alopecia appear to be the most frequent involvements encountered at inclusion, found in $37 \%$ of patients. The joint involvement, arthritis or inflammatory arthralgia, was the most frequent clinical involvement, found in $82 \%$ of all patients. This was followed by the hematological and cutaneous involvement, as well as by alopecia ( $69 \%, 65 \%$, and $65 \%$, respectively).

Due to lupus' specific heterogeneity, the description of different specific subgroups of this pathology was attempted. One cluster was defined by the presence of S's S and possible peculiar characteristics like older age, oral ulcers, Raynaud's phenomenon, anti-Ro and anti-La antibodies, lower occurrence of renal involvement, and positive anti-DNA. (11) Also, clusters based on the presence of active disease with major involvements, gender, age of onset or disease duration were proposed. (12) One search according to the diagnostic codes used, found that patients with SLE as main diagnostic have younger age and less comorbidities, and they are also closer to the treatment initiation. On the contrary, SLE as second diagnosis is generally identified in older patients with a higher comorbidity level. (13)

Regarding S's S occurrence, it is more frequently present in late onset SLE patients, (32) i.e. $27 \%$ in the older group compared to $12 \%$ in younger patients. (26) Moreover, Stefanidou S. (4) et al reported higher rates of occurrence in female patients. Also, Raynaud phenomenon appears to be more often observed in lupus females than in males (4) and rates as high as $44 \%$ were reported for the Raynaud phenomenon in lupus (30). On the contrary, APS appears more frequent in male than in female patients (4). APS prevalence also appears to differ according to patients' ethnicity, ranging from $12 \%$ in Chinese and $28 \%$ in Indian patients (36)

In our sample, we identified $44 \%$ patients with associated Raynaud phenomenon, $18 \%$ patients with S's S, and 29\% with secondary APS.

Of the other associated comorbidities, osteoporosis is found in up to $15 \%$ of lupus patients $(4,30)$. The reported rates of diabetes vary from $5 \%(1,40)$ to $12 \%$ (30). Barnado A (30) et al identified higher rates of hypertension occurrence in lupus patients 
than in controls, $62 \%$ vs. $36 \%$. Urowitz MB (43) et al found 97 vascular events in 1,249 patients, of which 13 patients with myocardial infarction, 24 patients with heart failure, and 23 patients with stroke.

The disease activity scores usually used in lupus are generally considered to have similar accuracy. Disease activity appears to be greater in patients with juvenile onset (32). Urowitz MB (19) et al reported a SLEDAI score at inclusion of $5.9 \pm 5.5$ points. Fernandez M. (3) et al observed a SLAM score of 11 points in Texan, 7 points in Puerto Rican, 11 points in African American, and 8 points in Caucasian lupus patients.

In accordance with disease activity, corticosteroid average daily doses were lower in Caucasian patients $(6 \mathrm{mg})$ than in Texan $(11 \mathrm{mg})$ or African American patients $(13 \mathrm{mg})$. Conversely, glucocorticoid doses in Puerto Rican patients were around $10 \mathrm{mg}$ daily (3). Overall, around $84-95 \%$ of the lupus patients included were receiving glucocorticoid treatment (3). Lower rates of ongoing glucocorticoids therapy was also reported, $70 \%$ by Bruce IN (40) et al with $44 \mathrm{mg} /$ day as the highest dose and 24 $\mathrm{mg}$ /day as the average posology. In SLE patients with active joint involvement, doses less than $7.5 \mathrm{mg}$ daily were found in $53 \%$ of cases and more than $7.5 \mathrm{mg}$ daily in $16 \%$ of subjects (44). The large number of adverse effects in the case of glucocorticoids' long term use makes the tapering below $5 \mathrm{mg}$ a very important task in the lupus management. There are some factors identified to predict a successful tapering, like younger age, Caucasian race, a higher level of education, absence of proteinuria, and, as we might assume, disease remission (45). Moreover, the morbidity risk seems higher in SLE patients under long-term corticosteroids (46). In lupus patients, it is generally difficult to determine the absolute impact of glucocorticoids compared to disease activity itself as the treatment in lupus is administrated in direct correlation to disease activity. Antimalarials (Hydroxychloroquine) are now recommended in all SLE patients without contraindications, allergies or adverse effects. Hydroxychloroquine is largely recommended in SLE patients as it was observed to be associated with lower risk of damage (21), and it was also proved to be protective in relation to pre-existing (38) and to future damage (47). In some papers, Hydroxychloroquine use was reported in relatively low percents like $41 \%$ (44) or $67 \%$ (40). Much larger rates of Hydroxychloroquine were presented by other authors, such as $83-85 \%$ (3) or $82-91 \%$ (35).
Overall immunosuppressive treatment is present in up to $40 \%$ of the lupus patients (40). Methotrexate therapy proved to be efficient in these subjects (48) and its use was reported in $10 \%$ of patients in certain samples (44) and up to $19 \%$ of the lupus population with rural residency (35). Azathioprine use also varies largely, from $10-17 \%$ (3) to rates as high as $41 \%$ (44). Cyclophosphamide therapy is reported differently according to the route of the administration, intravenous or per os, from $1 \%$ of patients to up to $8-21 \%(3,44)$. In lupus nephritis, low doses of Cyclophosphamide followed by Azathioprine have similar results as the high Cyclophosphamide doses alone (41). Mycophenolate Mofetil proved to be a very useful therapeutic option in lupus management, with a glucocorticoid-sparing effect. (49) Its use was observed in 13\% SLE patients (44).

In our group, the corticosteroid treatment was present in $81 \%$ of patients with median daily doses of $10 \mathrm{mg}$ and a median therapy duration of 6 years. Also, Hydroxychloroquine was present in a high proportion of the lupus patients analyzed, $81 \%$. Cyclophosphamide use was lower in our lot than in previously reported samples because it is generally used only in intravenous administration, as pulse therapy; also, none of the patients included was under per os treatment. Treatment with Mycophenolate Mofetil is less used than expected; this is due to the high cost of this treatment, a cost that is not covered by our national health insurance company.

Since lupus treatment, be it glucocorticoid or immunosuppressive, in terms of both dosing and duration of therapy, is determined by SLE disease activity. It is therefore very difficult to determine what are the main factors that cause damage, given that there is also a cumulative effect, most probably.

In regard to damage, this is defined by a SLICC index score equal to or more than 1 point. An increased maximum daily corticosteroid dose determines greater damage (47). Furthermore, an increase of $1 \mathrm{mg}$ daily in prior Prednisone dose is associated with around $2.8 \%$ increase of the risk of developing new damage (50). The damage in lupus patients is higher than in general population and average SLICC score of 0.3-1.0 points were reported (3). Presence of damage in SLE patients is predictive of future new damage development and also of higher mortality (40). In the Lupus Hopkins Cohort, a rate of yearly damage increase of 0.13 was approximated (51). Factors like older age, male sex, African American descent, low income or education, hypertension, 
presence of lupus anticoagulant, low complement, anti-DNA positivity, and proteinuria are predictive of future damage occurrence (51).

Significant improvement was achieved in lupus patients' survival during the last 50 years, but even so mortality rates remain higher than in the general population. Infections and disease flares are the main causes of mortality during the first years after lupus diagnosis, while cardiovascular pathology takes over after more than 20 years of disease duration (34).

\section{CONCLUSION}

In this descriptive cross-sectional study, we presented data related to SLE patients' general characteristics, biological parameters, immunological features, disease scores, and treatment principles. All data were collected in patients from single-center sample and bring important information on SLE population from an eastern European country.

\section{Abbreviations}

Abs - antibodies; APLAs - antiphospholipid antibodies; APS - antiphospholipid syndrome; aPL - antiphospholipid; aCL - anticardiolipin; a $32 \mathrm{GPI}$ - anti- $\beta 2$ glycoprotein I; APS - antiphospholipid syndrome; CRP - C-reactive protein; ECLAM European Consensus Lupus Activity Measure; DVT - deep vein thrombosis; ESR - erythrocyte sedimentation rate; LAC - lupus anticoagulant; SLE - systemic lupus erythematosus; S's S - Sjogren's syndrome; SLAM - Systemic Lupus Activity Measure; SLE - Systemic Lupus Erythematosus; SLEDAI - Systemic Lupus Erythematosus Disease Activity Index; SLICC - Systemic Lupus International Collaborating Clinics.

\section{Conflict of interests}

The authors declare that there is no conflict of interests regarding the publication of this paper.

Acknowledgement/Founding

Nothing to declare

Authors' contribution

All authors contributed equal

\section{REFERENCES}

1. Rúa-Figueroa I., López-Longo F.J., Calvo-Alén J., GalindoIzquierdo M., Loza E., García de Yebenes M.J., Pego-Reigosa J.M. Grupo de trabajo en Enfermedades Autoinmunes Sistémicas de la Sociedad Española de Reumatología (EAS-SER); Unidad de Investigación de la Sociedad Española de Reumatología (UI-SER). National registry of patients with systemic lupus erythematosus of the Spanish Society of Rheumatology:objectives and methodology. Reumatol Clin. 2014 Jan-Feb; 10(1):17-24.

2. Furst D.E., Clarke A.E., Fernandes A.W., Bancroft T., Greth W., lorga S.R. Incidence and prevalence of adult systemic lupus erythematosus in a large US managed-care population. Lupus. 2013; 22(1):99-105.

3. Fernández M., Alarcón G.S., Calvo-Alén J., Andrade R., McGwin G. Jr, Vilá L.M., Reveille J.D. LUMINA Study Group. A multiethnic, multicenter cohort of patients with systemic lupus erythematosus (SLE) as amodel for the study of ethnic disparities in SLE. Arthritis Rheum. 2007 May 15; 57(4):576-84.

4. Stefanidou S., Benos A., Galanopoulou V., Chatziyannis I., Kanakoudi F., Aslanidis S., Boura P., Sfetsios T., Settas L., Katsounaros M., Papadopoulou D., Giamalis P., Dombros N., Chatzistilianou M., Garyfallos A. Clinical expression and morbidity of systemic lupus erythematosus during a post-diagnostic 5-year follow-up: amale:female comparison. Lupus. 2011 Oct; 20(10):1090-4.

5. Jiménez S., Cervera R., Font J., Ingelmo M. The epidemiology of systemic lupus erythematosus. Clin Rev Allergy Immunol. 2003 Aug; 25(1):3-12

6. Oliveira-Santos M., Verani J.F., Klumb E.M., Albuquerque E.M. Evaluation of adherence to drug treatment in patients with systemic lupus erythematosus inBrazil. Lupus. 2011 Mar; 20(3):320-9.

7. Lerang K., Gilboe I., Garen T., Thelle D.S., Gran J.T. High incidence and prevalence of systemic lupus erythematosus in Norway. Lupus. 2012; 21(12):1362-9.

8. Abid N., Khan A.S., A.I. Otaibi F.H. Systemic lupus erythematosus (SLE) in the eastern region of Saudi Arabia. A comparative study. Lupus. 2013 Dec; 22(14):1529-33.

9. Golder V., Connelly K., Staples M., Morand E,. Hoi A. Association of Asian ethnicity with disease activity in SLE: an observational study from the Monash Lupus Clinic. Lupus. 2013 Nov; 22(13):1425-30.
10. Gilkeson G., James J., Kamen D., Knackstedt T., Maggi D., Meyer A,. Ruth N. The United States to Africa lupus prevalence gradient revisited. Lupus. 2011 Oct; 20(10):1095-103.

11. Baer A.N., Maynard J.W., Shaikh F., Magder L.S., Petri M. Secondary Sjogren's syndrome in systemic lupus erythematosus defines a distinct disease subset. J Rheumatol. 2010 Jun; 37(6):1143-9.

12. Terao C., Yamada R., Mimori T., Yamamoto K,. Sumida T. A nationwide study of SLE in Japanese identified subgroups of patients with clear signs patterns and associations between signs and age or sex. Lupus. 2014 Nov; 23(13):1435-42.

13. Canora-Lebrato J., Barba-Martín R,. Perales-Fraile I., MarcoMartínez J., Plaza-Cantelli S., Zapatero-Gaviria A. Description of hospital discharges in patients with systemic lupus erythematosus. Rev Clin Esp. 2012 Oct; 212(9):432-9.

14. Tucker L.B., Uribe A.G., Fernández M., Vilá L.M., McGwin G., Apte M., Fessler B.J., Bastian H.M., Reveille J.D., Alarcón G.S. Adolescent onset of lupus results in more aggressive disease and worse outcomes: results of a nested matchedcase-control study within LUMINA, a multiethnic US cohort (LUMINA LVII). Lupus. 2008 Apr; 17(4):314-22.

15. Shaikh M.A., Memon I., Ghori R.A. Frequency of anaemia in patients with systemic lupus erythematosus at tertiary care hospitals. J Pak Med Assoc. 2010 Oct; 60(10):822-5.

16. Ugarte-Gil M.F., Pons-Estel G.J., Molineros J., Wojdyla D., McGwin G. Jr, Nath S.K., Pons-Estel B.A., Alarcón-Riquelme M., Alarcón G.S. Disease features and outcomes in United States lupus patients of Hispanic origin and their Mestizo counterpartsin Latin America: a commentary. Rheumatology (Oxford). 2015 Sep 27. pii: kev280.

17. Burgos P.I., McGwin G. Jr, Reveille J.D., Vilá L.M., Brown E.E., Alarcon G.S. Is familial lupus different from sporadic lupus? Data from LUMINA (LXXIII), a multiethnic US cohort. Lupus. 2010 Oct; 19(11):1331-6

18. Arkema E.V., Simard J.F. Cohort profile: systemic lupus erythematosus in Sweden: the Swedish Lupus Linkage (SLINK) cohort. BMJ Open. 2015 Aug 14; 5(8):e008259.

19. Urowitz M.B., Gladman D.D., Ibañez D., Fortin P.R., Bae S.C., Gordon C., Clarke A., Bernatsky S., Hanly J.G., Isenberg D., Rahman A., Sanchez-Guerrero J., Wallace D.J., Ginzler E., 
Alarcón G.S., et al. Evolution of disease burden over five years in a multicenter inception systemic lupus erythematosus cohort. Arthritis Care Res (Hoboken). 2012 Jan; 64(1):132-7.

20. Medina-Quiñones C.V., Ramos-Merino L., Ruiz-Sada P., Isenberg $\mathbf{D}$. Analysis of Complete Remission in Lupus Patients over a period of 32 years. Arthritis Care Res (Hoboken). 2015 Nov 10.

21. Petri M., Orbai A.M., Alarcón G.S. et al. Derivation and validation of the Systemic Lupus International Collaborating Clinics classification criteria for systemic lupus erythematosus. Arthritis Rheum. 2012 Aug; 64(8):2677-86.

22. Liang M.H., Socher S.A., Larson M.G. et al. Reliability and validity of six systems for the clinical assessment of disease activity in systemic lupus erythematosus. Arthritis Rheum. 1989 Sep:32(9):1107-18.

23. Vitali C., Bencivelli W., Isenberg D.A .et al. Disease activity in systemic lupus erythematosus: report of the Consensus Study Group of the European Workshop for Rheumatology Research. II. Identification of the variables indicative of disease activity and their use in the development of an activity score. The European Consensus Study Group for Disease Activity in SLE. Clin Exp Rheumatol. 1992 Sep-Oct; 10(5):541-7.

24. Bombardier C., Gladman D.D., Urowitz M.B. et al. Derivation of the SLEDAI. A disease activity index for lupus patients. The Committee on Prognosis Studies in SLE. Arthritis Rheum. 1992 Jun; 35(6):630-40.

25. Gladman D., Ginzler E., Goldsmith C. et al. The development and initial validation of the Systemic Lupus International Collaborating Clinics/American College of Rheumatology damage index for systemic lupus erythematosus. Arthritis Rheum. 1996 Mar; 39(3):363-9.

26. Alonso M.D., Martinez-Vazquez F., de Teran T.D., Miranda-Filloy J.A., Dierssen T., Blanco R., Gonzalez-Juanatey C., Llorca J., Gonzalez-Gay M.A. Late-onset systemic lupus erythematosus in Northwestern Spain: differences with early-onset systemic lupuserythematosus and literature review. Lupus. 2012 Sep; 21(10):1135-48.

27. das Chagas Medeiros M.M., Bezerra M.C., Braga F.N., da Justa Feijão M.R., Gois A.C., Rebouças V.C., de Carvalho T.M., Carvalho L.N., Ribeiro Á.M. Clinical and immunological aspects and outcome of a Brazilian cohort of 414 patients with systemic lupus erythematosus (SLE): comparison between childhood-onset, adult-onset, and late-onset SLE. Lupus. 2015 Sep 23.

28. Andrade R.M., Alarcón G.S., Fernández M., Apte M., Vilá L.M., Reveille J.D. LUMINA Study Group. Accelerated damage accrual among men with systemic lupus erythematosus: XLIV. Results from a multiethnic US cohort. Arthritis Rheum. 2007 Feb; 56(2):622-30.

29. Pamuk O.N., Akbay F.G., Dönmez S., Yilmaz N., Calayir G.B., Yavuz S. The clinical manifestations and survival of systemic lupus erythematosus patients in Turkey: report from twocenters. Lupus. 2013 Nov; 22(13):1416-24.

30. Barnado A., Wheless L., Meyer A.K., Gilkeson G.S., Kamen D.L. Quality of life in patients with systemic lupus erythematosus (SLE) compared with related controls within aunique African American population. Lupus. $2012 \mathrm{Apr}$; 21(5):563-9.

31. Catoggio L.J., Soriano E.R., Imamura P.M., Wojdyla D., Jacobelli S., Massardo L., Chacón Díaz R., Guibert-Toledano M., Alvarellos A., Saurit V., Manni J.A., et al. Grupo Latino Americano De Estudio del Lupus (GLADEL). Late-onset systemic lupus erythematosus in Latin Americans: a distinct subgroup? Lupus. $2015 \mathrm{Jul} ; 24(8): 788-95$.

32. Choi J.H., Park D.J., Kang J.H., Yim Y.R., Lee K.E., Lee J.W., Wen L., Kim T.J., Park Y.W., Lee J.K., Lee S.S. Comparison of clinical and serological differences among juvenile-, adult-, and late-onset systemic lupuserythematosus in Korean patients. Lupus. 2015 Oct; 24(12):1342-9.

33. Li M., Zhang W., Leng X., Li Z., Ye Z., Li C., Li X., Zhu P., Wang Z., Zheng Y., Li X., Zhang M., Zhang F., Zhao Y., Zeng X.; CSTAR co-authors. Chinese SLE Treatment and Research group (CSTAR) registry: I. Major clinical characteristics of Chinese patients with systemic lupus erythematosus. Lupus. 2013 Oct; 22(11):1192-9.

34. Voss A., Laustrup H., Hjelmborg J., Junker P. Survival in systemic lupus erythematosus, 1995-2010. A prospective study in a Danish community. Lupus. 2013 Oct; 22(11):1185-91.
35. Pons-Estel G.J., Saurit V., Alarcón G.S., Hachuel L., et al. The impact of rural residency on the expression and outcome of systemic lupus erythematosus: data from a multiethnic Latin American cohort. Lupus. 2012 Nov;21(13):1397-404.

36. Jasmin R., Sockalingam S., Cheah T.E., Goh K.J. Systemic lupus erythematosus in the multiethnic Malaysian population: disease expression and ethnic differences revisited. Lupus. 2013 Aug; 22(9):967-71.

37. Feng X., Zou Y., Pan W., Wang X., Wu M., Zhang M., Tao J., Zhang Y., Tan K., Li J., Chen Z., et al. Associations of clinical features and prognosis with age at disease onset in patients with systemic lupus erythematosus. Lupus. 2014 Mar; 23(3):327-34.

38. Cipriano E., Ceccarelli F., Massaro L., Spinelli F.R., Alessandri C., Perricone C., Valesini G., Conti F. Joint involvement in patients affected by systemic lupus erythematosus: application of the swollen to tenderjoint count ratio. Reumatismo. 2015 Sep 16; 67(2):62-7

39. Servais G., Karmali R., Guillaume M.P., Badot V., Duchateau J., Corazza F. Anti DNA antibodies are not restricted to a specific pattern of fluorescence on HEp2 cells. Clin Chem Lab Med. 2009; 47(5):543-9.

40. Bruce I.N., O'Keeffe A.G., Farewell V., Hanly J.G., Manzi S., et al. Factors associated with damage accrual in patients with systemic lupus erythematosus:results fromthe Systemic Lupus International Collaborating Clinics (SLICC) InceptionCohort. Ann Rheum Dis. 2015 Sep; 74(9):1706-13.

41. Houssiau F.A., Vasconcelos C., D‘Cruz D., Sebastiani G.D., de Ramon Garrido E., Danieli M.G., et al. Early response to immunosuppressive therapy predicts good renal outcome in lupus nephritis: lessons from long-term followup of patients in the EuroLupus Nephritis Trial. Arthritis Rheum. 2004 Dec; 50(12):3934-40.

42. Shaikh M.A., Memon I., Ghori R.A. Frequency of anaemia in patients with systemic lupus erythematosus at tertiary carehospitals. J Pak Med Assoc. 2010 Oct; 60(10):822-5.

43. Urowitz M.B., Gladman D., Ibañez D., Bae S.C., SanchezGuerrero J., Gordon C., Clarke A., Bernatsky S., Fortin P.R., et al. Systemic Lupus International Collaborating Clinics. Atherosclerotic vascular events in a multinational inception cohort of systemic lupus erythematosus. Arthritis Care Res (Hoboken). 2010 Jun; 62(6):881-7.

44. Fischin J., Chehab G., Richter J.G., Fischer-Betz R., WinklerRohlfing B., Willers R., Schneider M. Factors associated with pain coping and catastrophising in patients with systemic lupus erythematosus: a cross-sectional study of the LuLa-cohort. Lupus Sci Med. 2015 Nov 12; 2(1):e000113.

45. Zahr Z.A., Fang H., Magder L.S., Petri M. Predictors of corticosteroid tapering in SLE patients: the Hopkins Lupus Cohort. Lupus. 2013 Jun; 22(7):697-701.

46. Zonana-Nacach A., Barr S.G., Magder L.S., Petri M. Damage in systemic lupus erythematosus and its association with corticosteroids. Arthritis Rheum. 2000 Aug; 43(8):1801-8.

47. Shaharir S.S., Ghafor A.H., Said M.S., Kong N.C. A descriptive study of the factors associated with damage in Malaysian patients with lupus nephritis. Lupus. 2014 Apr; 23(4):436-42.

48. Sakthiswary R., Suresh E. Methotrexate in systemic lupus erythematosus: a systematic review of its efficacy. Lupus. 2014 Mar; 23(3):225-35.

49. Lourdudoss C., Vollenhoven R.V. Mycophenolate mofetil in the treatment of SLE and systemic vasculitis: experience at a single university center. Lupus. 2014 Mar; 23(3):299-304

50. Al Sawah S., Zhang X., Zhu B., Magder L.S., Foster S.A., likuni N., Petri M. Effect of corticosteroid use by dose on the risk of developing organ damage over time in systemic lupuserythematosus-the Hopkins Lupus Cohort. Lupus Sci Med. 2015 Mar 11; 2(1):e000066.

51. Petri M., Purvey S., Fang H., Magder L.S. Predictors of organ damage in systemic lupus erythematosus: the Hopkins Lupus Cohort. Arthritis Rheum. 2012 Dec; 64(12):4021-8. 